\title{
High-performance electric arc source of ultraviolet radiation to ozone generate
}

\author{
Andrey Veremeychik ${ }^{1, *}$, Evgeny Dmukhaylo ${ }^{1}$, Sergey Onysko ${ }^{1}$, Mikhail Sazonov ${ }^{1}$, Vitaly \\ Khvisevich $^{1}$ \\ ${ }^{1}$ Brest State Technical University, Moskovskaya str. 267, Brest, 224017, Belarus
}

\begin{abstract}
Studies of electric arc combustion in the swirling flow of a cylindrical discharge chamber of a plasma torch at oxygen consumption of $10-160 \mathrm{~g} / \mathrm{s}$ are carried out. It is established that the electric field strength is constant along the channel at the initial section of the arc, and the length of this section is determined. On the basis of the similarity theory in a wide range of changes in the parameters of the plasma torch, methods for determining the electric field strength of the arc and the length of the initial section are obtained. The length of the plasma torch is calculated, which mainly includes the length of the initial section, where the voltage is constant, and the current-voltage characteristics. The design of the plasma torch was created. Theoretical studies of near-electrode processes at the cathode and anode were carried out, on the basis of which electrode materials were selected and cathode and anode structures were created that provide high thermal efficiency and service life of the plasma torch. The developed plasma torch can be used as a highly efficient arc source of ultraviolet radiation for generating ozone, for heating oxygen, as well as in metallurgy, chemical industry, for example, the production of titanium dioxide and ozonation.
\end{abstract}

Keywords: plasma torch, electric arc, ozone, ultraviolet radiation, current-voltage characteristics, voltage.

\section{Introduction}

The field of ozone usage has expanded significantly and new research in this direction is being intensively carried out all over the world in recent years. The rapid development of technologies using ozone is facilitated by its ecological purity. Ozone forms saturated oxides during the reactions unlike other known oxidants. In this case, unused ozone is decomposed into atomic and molecular oxygen. All these products as a rule do not pollute the environment and do not lead to the formation of carcinogenic substances as for example when oxidized with chlorine or fluorine.

The most economically profitable way of producing ozone on an industrial scale is currently considered to be its synthesis in electric discharges of oxygen or oxygencontaining gas mixtures. A number of articles have been published concerning water purification using gas electric discharges over the past (10 - 15) years. Most of this research

*Corresponding author: vai_mrtm@bstu.by 
is related to the oxidative degradation (destruction) of organic pollutants using nonequilibrium plasma. Improved oxidation processes which include the formation of highly reactive chemical oxidants ( such as $\mathrm{O}, \mathrm{OH}, \mathrm{O}_{3}, \mathrm{H}_{2} \mathrm{O}_{2}$ ) have become an important step in accelerating the oxidation process and hence the breakdown of a wide range of organic pollutants in water.

Traditional approaches and technical solutions in the field of water treatment are often ineffective for the treatment and disposal of wastewater containing toxic, biodegradable and difficult to oxidize organic pollutants. In this regard, water purification technologies based on the use of strong oxidants are promising.

Due to the constant complication of the composition of wastewater, in particular due to biologically intractable and toxic organic compounds, technologies based on the use of various oxidants are promising.

In terms of its oxidizing capacity, ozone (redox potential 2,07 V) ranks third among the known oxidants, inferior to fluorine (oxidizing potential 2,41 V) and oxygen fluoride while chlorine (oxidizing potential $1,73 \mathrm{~V}$ ) is in the eighth place and ordinary oxygen $\left(\mathrm{O}_{2}\right)$ is only in the thirteenth place. The reactions of ozone with aromatic compounds formed the basis of modern technologies for deodorization of various environments, rooms, drinking and waste waters. The advantages of using ozone in the processes of purification and disinfection of water, air and other liquid and gaseous areas are generally recognized. Currently, about $95 \%$ of drinking water in Europe is ozone treated. In the USA, the process of transferring water supply systems from chlorination to ozonation is underway [1].

\section{Ozone and its usage}

Currently, ozonation is the only universal method of water treatment that allows to effectively affect a large number of various pollutants of artificial and natural origin with the simultaneous disinfection of water [1]. Long-term experience in the use of ozone and the operation of ozonation installations convinces that this method is highly effective. Further improvement of the ozonation technique will eliminate the disadvantages inherent in the method and it will be widely used.

In [2] are described methods for measuring odor at treatment facilities, the main methods used to reduce emissions of foul-smelling substances from wastewater disposal facilities are described.

Wastewater treatment of industrial enterprises using ozonation is one of the most promising and modern methods [3]. Wastewater ozonation can achieve the following goals:

- oxidation of organic and inorganic compounds;

- discoloration of water;

- deodorization of water containing substances of biological origin and contaminated with organic substances;

- treatment of effluents containing oil, oil products and phenols;

- treatment of effluents containing nitro compounds, carcinogenic and other substances;

- wastewater treatment after biological treatment;

- purification of acetone-containing and hydrogen sulfide-containing waters.

Ozone destroys all known microorganisms: viruses, bacteria, fungi, algae, their spores, cysts, etc. and acts very quickly - within a few minutes. Ozone removes unpleasant odors and does not form toxic by-products. Ozone destroys microorganisms 300 to 3000 times faster than any other disinfectant.

In crop production, ozone is currently used in the following areas:

- stimulation of plant cultivation by reducing microbial contamination of the plants themselves, soil and air as well as increasing the synthesis and accumulation of nutrients; 
- pre-sowing treatment of agricultural crops in order to increase their sowing qualities and yield properties, as well as resistance to adverse influences;

- controlling plant pests and diseases and reducing the use of herbicides and pesticides;

- the use of an ozone-air mixture as a drying agent;

- conservation and preservation of agricultural products, including in a wet state, reducing energy consumption during drying, reducing losses during storage;

- reducing the toxicity of harmful substances contained in agricultural products.

Crop products are often heavily contaminated with various infections, mold as well as small insects it can lead to significant losses during storage and processing and is especially dangerous, contributes to the spread of infectious diseases (staphylococcus, E. coli, salmonella, etc.).

The use of ozone-air mixtures allows:

- accelerate the processing of grain, reduce its energy intensity, ensure an increase in sowing quality and prevent spoilage;

- to increase the terms of safe storage of grain $(1,5-2)$ times, to increase seed quality by $15 \%$;

- to reduce the duration of low-temperature drying and energy consumption for drying grain by $(15-20) \%$;

- to reduce the viability of mold and leads to the destruction of toxins.

According to [3], one of the main ways to increase the yield of agricultural crops is to protect plants from diseases, in particular, from those phytopathogens the spores of which are localized on the surface of seeds. The most harmful of these are pathogens of hard smut and root rot. Losses of grain crops from these diseases can reach $(20-35) \%$. One of the ways to solve this problem is to use ozone. It is known that at an ozone concentration of about $2 \mathrm{mg} / \mathrm{m}^{3}$ and a 30-minute treatment, corn, wheat, barley and oats are sterilized from all types of microorganisms. When treating barley seeds with an ozone-air mixture with ozone concentrations of $6 \mathrm{mg} / \mathrm{m}^{3}$ and $10 \mathrm{mg} / \mathrm{m}^{3}$, the yield was $12,0 \%$ and $17,5 \%$ higher than when treated with pesticides. Also, according to field trials, an increase in yield was recorded for wheat $-22 \%$, peas $-11 \%$, buckwheat $-31 \%$.

In [4], the dynamics of the state of beetles and insects in grain and grain products after their treatment with ozone was studied. It is shown that when using an ozone-air mixture with an ozone concentration of $1 \mathrm{~g} / \mathrm{m}^{3}$ on the first day after treatment, a large number of paralyzed individuals are noted, which are not able to restore their state to normal and always die on the following days.

Recently, scientific researches have appeared on the effectiveness of the use of ozone in the fight against coronavirus. More and more clinical data is emerging on the successful application of "ozone therapy for coronavirus". It turned out that physiotherapy treatment with ozone can prevent the transition of COVID-19 to a severe form and reduce the need for potent medications. The pioneers in the application of this method of physiotherapy for COVID-19 were the countries that took the especially powerful blow of the new viral infection (USA, Spain, Italy, China, etc.). US Doctors R. Rowan and H. Robins report on the effectiveness and economic benefits of ozone therapy for the treatment of COVID-19. There is evidence of successful experience in the use of ozone against the SARS-CoV-2 virus in Romania, Georgia, Peru, Chile, Ecuador, Turkey and other countries [5].

The official expert opinion of the International Scientific Committee for Ozone Therapy ISCO3 on the use of ozone in the fight against ARVI infection with the COVID-19 strain is given in [6]. It provides a detailed explanation on whether ozone is effective in combating coronavirus. The International Scientific Committee on Ozone Therapy ISCO3 together with WHO (World Health Organization) officially declare that "there are currently no vaccines or special pharmaceutical treatments for COVID-19," therefore alternative methods of limiting the spread of the virus are being developed and considered. It is known 
that the virus lives on surfaces for a long time (furniture, door handles, elevator buttons, handrails, etc.) room ozonation allows you to sterilize the room with high efficiency and destroy all strains of the virus and infections. Ozonation is much more effective than sprays and disinfectants since it has a deep penetration rate into surfaces and crevices and, unlike chemicals, does not leave behind odors and harmful traces as it is natural gas. The room becomes completely safe for a person. At this difficult time, all public places that are allowed to be visited and these are medical institutions, educational institutions, shops, courtrooms, hairdressers, beauty salons, office and industrial premises need treatment (disinfection).

\section{Ozone synthesis}

International Scientific Committee on Ozone is formed in a gas environment containing oxygen if conditions arise in which oxygen dissociates into atoms. This is possible in all forms of electric discharge: glow, arc, spark, corona, surface, barrier, electrodeless, etc. The main reason for dissociation is the collision of molecular oxygen with electrons accelerated in an electric field. In addition to the discharge, the dissociation of oxygen is caused by ultraviolet radiation with a wavelength of less than $240 \mathrm{~nm}$ and various high-energy particles: $\alpha$-, $\beta$-, $\gamma$-particles, $\mathrm{X}$-rays, etc.

There is a group of reactions as a result of which ozone decomposes in almost all sources of ozone formation. These are thermal decomposition in the volume and on the walls of the reactor, its reactions with radicals and excited particles, reactions with additives and impurities that can come into contact with oxygen and ozone.

The main methods for the synthesis of ozone:

- Photochemical method isthe main share of ozone produced on Earth in nature is formed by this method. The main area of its use is the production of medium and low ozone concentrations. In practice, mercury and excimer xenon lamps are used to produce ozone by this method.

- Barrier discharge is a discharge that occurs between two dielectrics or a dielectric and a metal. Due to the fact that the electrical circuit is broken by a dielectric, power is supplied only with alternating current. At low capacities, the ozonizerneed not be cooled, since the released heat is carried away with the flow of oxygen and ozone.Ozone is also synthesized in arc ozonizers (plasmatrons), in glow ozone generators (lasers) and surface discharge in industrial production.

- Corona discharge - this method of producing ozone is the most reliable and efficient of all known and therefore is most widely used in industrial conditions. It features an optimal ratio of energy consumption to the concentration of generated ozone. A corona discharge occurs in a gas in a highly inhomogeneous electric field between two electrodes - high-voltage and grounded, separated by a gap (discharge gap) and a dielectric. Ozone is formed as a result of the dissociation of an oxygen molecule as a result of the action of the energy of electrons moving between the electrodes through the discharge gap. The ozone concentration depends on the voltage, its frequency, dielectric thickness, dielectric constant, as well as on the oxygen concentration in the working gas, which is determined by the type of working gas - dried or undried air, oxygen, as well as the working gas pressure in the discharge gap. A known method for the synthesis of ozone [7] in the corona discharge of direct and alternating current. It was established in [7] that in all cases of a corona discharge, there is a dependence of the formation of ozone on the material of the electrodes, as well as on the operating time of the ozonizer, which is explained by corrosion and sputtering of metal electrodes.

- Electrolytic synthesis method - usually aqueous solutions of perchloric or sulfuric acid are used as an electrolyte, electrodes are made of platinum. The use of some acids has 
shown that they do not give up their oxygen during the formation of ozone. Therefore, the gross scheme should take into account only the decomposition of water $\left(\mathrm{H}_{2} \mathrm{O}+\mathrm{O}_{2} \rightarrow \mathrm{O}_{3}+2 \mathrm{H}++\mathrm{e}^{-}\right)$with possible intermediate formation of ions or radicals.

- The formation of ozone under the influence of ionizing radiation - ozone is formed in a number of processes accompanied by the excitation of an oxygen molecule either by light or by an electric field. When oxygen is irradiated by ionizing radiation, excited molecules can also arise and ozone is observed to form.

- Ozone formation in a microwave field - when a jet of oxygen was passed through a microwave field, ozone formation was observed. This process is poorly understood, although generators based on this phenomenon are often used in laboratory practice.

According to [8], the most economically profitable way of producing ozone on an industrial scale is currently considered to be its synthesis in electric discharges of oxygen or oxygen-containing gas mixtures. It should be noted that ozone electrosynthesis as a rule is a rather energy-intensive process.

A significant number of articles are devoted to the synthesis of ozone in electrical discharges [9-23]. The article [9] proposes a method for the synthesis of ozone in a combined discharge, in which the surface and barrier discharges are connected in series in an electric circuit, experimental studies of the characteristics of the synthesis of ozone from oxygen at the atmospheric pressure of this discharge are carried out depending on the parameters of the discharge circuit, voltage and gas flow rate. An ozonizer built on the basis of a combined discharge allows one to obtain high ozone concentrations up to $100 \mathrm{~g} / \mathrm{m}^{3}$ at an energy consumption of about $12 \mathrm{kWh} / \mathrm{kg}$. In [10], the influence of the source gas (dried air and oxygen) on the process of ozone synthesis in a barrier discharge, on the structure and parameters of ozonation stations, on the operating conditions of ozonation equipment, and on the economic indicators of the ozone production process is considered. The authors of [11] propose to use the synthesis of ozone in a corona discharge between coaxial electrodes under the influence of pulses up to $27 \mathrm{kV}$ with a duration of $25 \mathrm{~ns}$ with a repetition rate of $130 \mathrm{~Hz}$, while the efficiency of $\mathrm{O}_{3}$ formation reached $130 \mathrm{~g} / \mathrm{kWh}$.

In [12], a set of conditions and requirements for the discharge circuit necessary for the generation of ozone from air and oxygen with minimal specific energy consumption is considered, the possibility of generating ozone with an energy efficiency close to the thermochemical limit of $0.85 \mathrm{kWh} / \mathrm{kg} \mathrm{O}_{3}$ is shown, the possibility of water disinfection is shown using a corona flare discharge with energy consumption at the level of $1 \mathrm{kWh} / \mathrm{m}$.

\section{High performance plasma generator for wastewater ozonation process}

Electric arc gas heaters (plasmatrons) are widely used for stationary irradiation to the state of low-temperature plasma. Their use in industrial technologies has provided a variety of design solutions for plasma devices. The energy and electrophysical characteristics of plasmatronsare mainly determined by the geometric and gas-dynamic parameters of the discharge chamber [24-28]. Oxygen plasma generators are used in metallurgy, chemical industry, for example, titanium dioxide production and ozonation, and can also be used to produce ozone in various fields.

To obtain initial data for theoretical research, modeling and development of plasmatrons intended for the production of ozone, measurements of the electric field strength of an arc burning in oxygen were carried out. The nature of combustion is determined by the swirling flow and the speed of the gas flowing around the arc. The modes of formation of the boundary layer near the channel wall and flow around the arc strongly affect the processes of converting electrical energy into heat. 
Arc studies were carried out on an experimental plasmatron (Fig. 1) with a fixed arc length and geometrically similar electric discharge chambers. The inner electrode was a zirconium cathode $2 \mathrm{~mm}$ in diameter, sealed flush into a copper cage.

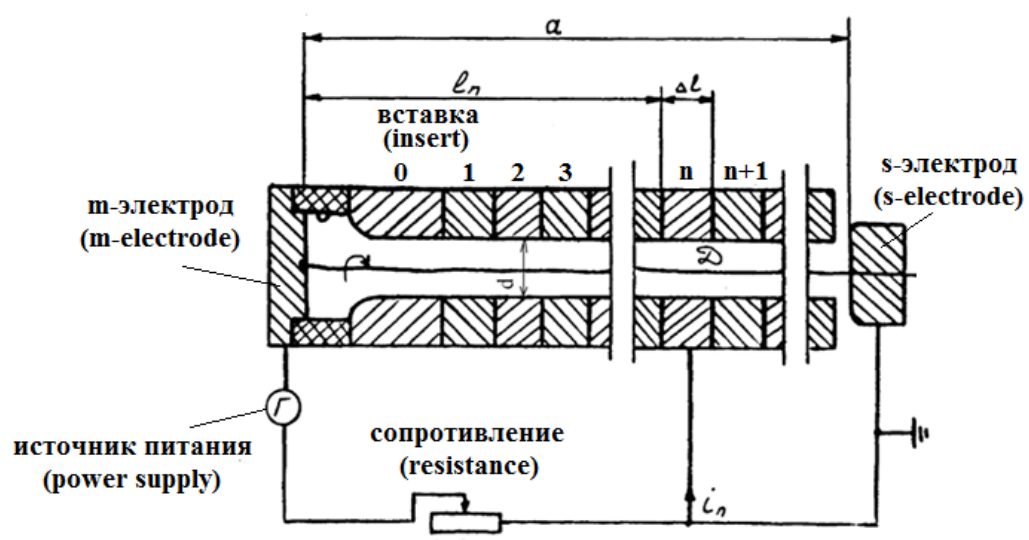

Fig. 1. Diagram of the experimental device.

A cylindrical discharge chamber is formed in this plasmatron with the help of sections in order to change the arc length and to measure the arc radiation, the development of the boundary layer and the length of its initial section where there is no convective heat exchange between the arc and the gas flow. This makes it possible to determine the length of the discharge chamber where the gas is exposed only to ultraviolet radiation.

The electric field strength along the arc E was determined by measuring the arc length, measuring the arc voltage [27]. The electric field strength of the arc was determined from the slope of the potential distribution curve along the $z$ axis. The ranges of parameter variation when investigating the arc in oxygen are as follows: diameter of the discharge chamber $(0,01-0,03) \mathrm{mm}$, distance between electrodes $(0.15-0.36) \mathrm{m}$, arc current $(30$ 180) A, oxygen consumption $(2-4) \mathrm{g} / \mathrm{s}$. A typical dependence of the electric field strength of the arc on the current I at a gas flow rate $G=4 \mathrm{~g} / \mathrm{s}$ is shown in Fig.2.

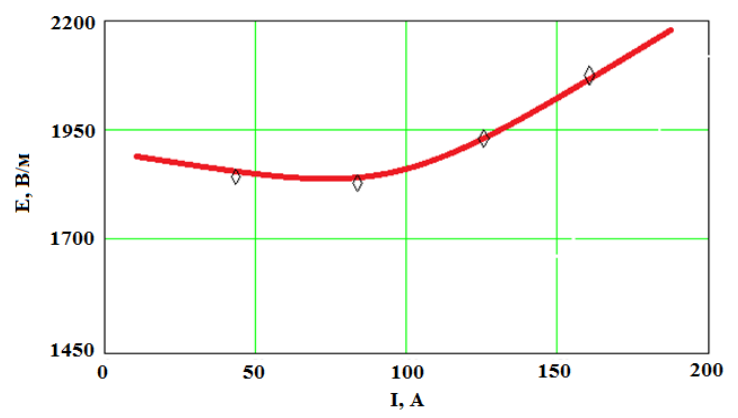

Fig. 2. The electric field strength of the arc in the oxygen flow at $\mathrm{d}=1 \mathrm{~cm}$.

A method for calculating plasmatrons has been developed on the basis of the similarity theory. The following criterion formula was obtained for calculating the $\mathrm{E}$ arc in an oxygen flow by processing the experimental results and generalizing them:

$$
E=3,17 \times 10^{-2}\left(\frac{G}{d}\right)^{0,15}(p d)^{0,13}\left(347-1 \times 10^{-2} \frac{I}{d}+9,26 \times 10^{-2} \frac{I^{2}}{d^{2}}\right) .
$$


Dimensions of quantities: E - V/m, G - kg/s, I - A, d - m, p - Pa.

Current-voltage characteristics of the arc were studied $[27,28]$ to compare the electric field along the arc in vortex flows of various gases.Plasmatron was developed and constructed the diagram of which is shown in Fig. 3 with the help of the developed technique using the criterion formula. The main elements of the plasmatron are the zirconium cathode, the ignition electrode and the anode. The ignition electrode is made of copper in the form of a washer section with an inner diameter of $d_{l}=16 \mathrm{~mm}$. The tested copper anode had a diameter $d_{2}=16 \mathrm{~mm}$. The anode length 1 varied from $90 \mathrm{~mm}$ to $150 \mathrm{~mm}$. The cathode, ignition electrode, anode and solenoid are intensively cooled with chemically purified water. Water is supplied to the plasma torch cooling system under pressure $(10-15) \mathrm{atm}$. To calculate the heat fluxes into the electrodes, the temperature of the water at the inlet and outlet of the plasmatron was determined using chromel-copel thermocouples.

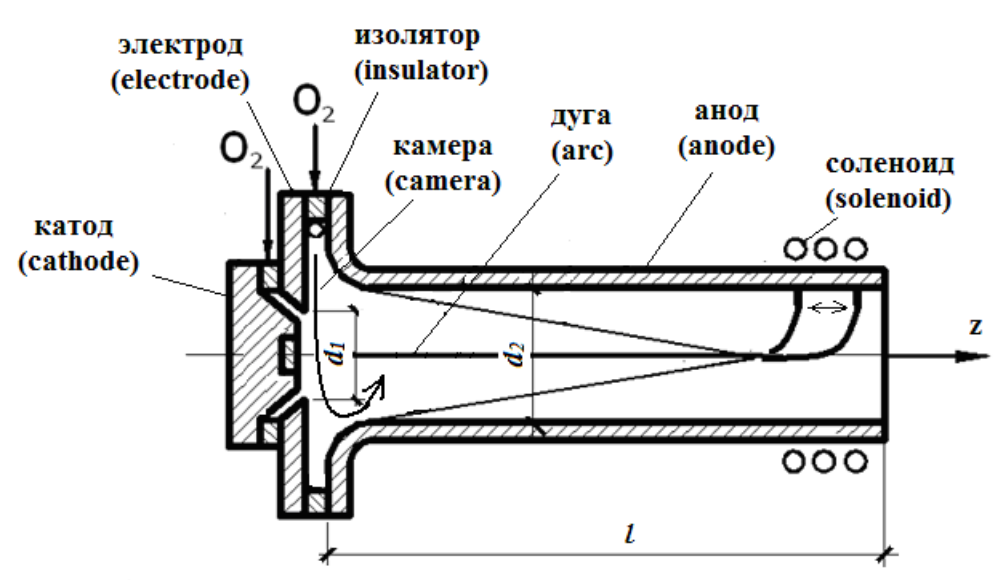

Fig. 3. Plasmatron diagram.

The oxygen pressure in front of the flow meters at the plasma torch inlet was $(4-8) \times 10^{5} \mathrm{~Pa}$. Oxygen was fed into the gap between the cathode and the ignition electrode through two tangential holes $1.2 \mathrm{~mm}$ in diameter located in a twist ring with an inner diameter of $50 \mathrm{~mm}$, oxygen was supplied at a rate of $(0,1-0,2) \mathrm{g} / \mathrm{s}$. The second swirl chamber located between the ignition electrode and the anode was supplied with gas through four tangential holes $2.4 \mathrm{~mm}$ in diameter located in a swirl ring with an inner diameter of $64 \mathrm{~mm}$. The total oxygen consumption varied from $0.5 \mathrm{~g} / \mathrm{s}$ up to $2.4 \mathrm{~g} / \mathrm{s}$. The plasmatron was powered from an APR-404 type power source with a rated no-load current of $600 \mathrm{~A}$ and a voltage of $900 \mathrm{~V}$. Because its external electrical characteristic is rigid and current-voltage characteristic of the arc is falling due to unstable arc burning; a stepwise ballast resistance is included in the power circuit in series with the arc in order to ensure its stable combustion. Plasmatronwas ignited using a high-voltage high-frequency oscillator with a voltage applied to the igniting electrode. A resistance $(10-20) \mathrm{Ohm}$ is connected between the ignition electrode and the anode via a contactor.

Current-voltage characteristic of the plasmatronwere studied. In addition, measurements of the arc radiation were carried out in the plasmatron section, cathode, anode and ignition electrode. This made it possible to calculate the efficiency of plasmatron, enthalpy and average mass temperature $T$ of the gas depending on the magnitude of the arc current and the length of the anode at different gas flow rates. It was found that the efficiency is equal 
to $(0,6-0,74)$. The diagram of the plasmatronis shown in Fig. 4. This plasmatron is a radiation generator. A reactor with tangential holes is installed at the outlet of the plasmatron through which waste water is supplied for quenching and mixing with $\mathrm{O}_{3}$.

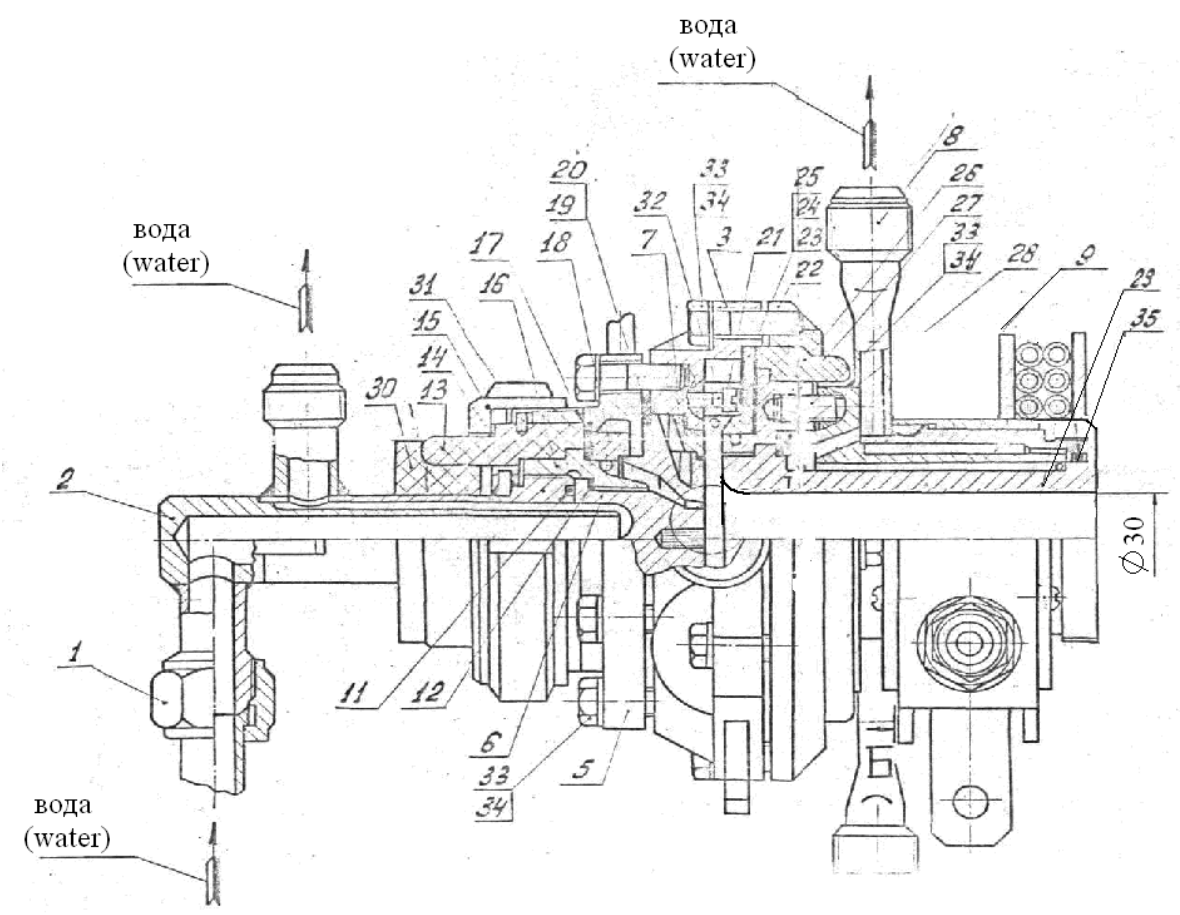

Fig. 4. General view of the plasmatron.

\section{Conclusion}

An experimental plasma installation was created, the current-voltage characteristics of the arc in the flow of oxygen and air at different arc lengths, the electric field strength along the arc and the length of its initial section were studied, and it was found that $\mathrm{E}_{\mathrm{n}}=$ const. The radiation along the arc is measured, which is constant at different distances from the cathode in this section of the arc.

Conducted theoretical research on the basis of similarity theory and research results are summarized as a dependency for electric field strength of the arc, the current-voltage characteristics of the arc length of the initial section, which allows to count the torches of the given power.

A radiation generator with a power of up to $0.5 \mathrm{MW}$ has been developed and created. The plasma torch was tested and the erosion characteristics of the electrodes were studied, which confirmed the high service life of the plasma torch.

\section{References}

1. V.A. Orlov. Ozonation of water. M.: Stroyizdat, 1984. 88 p. 
2. S.V. Svitskov, D.A. Danilovich, V.N. Azarov. Wastewater treatment plants as a source of unpleasant odor: causes, characteristics and methods of control // Water supply and sanitary engineering. No. 7. 2016. P. 24-43.

3. http://www.kaufmanntec.ru

4. G.L. Zakladnoy, M.A. Osman. Biological assessment of ozone as a means of combating pests of grain and grain products // Storage and processing of agricultural raw materials. No. 5, 2011. P. 8-9.

5. https://www.secret-dolgolet.ru/ozonoterapiya-ot-koronavirusa

6. Adriana Schwartz, Gregorio Martínez-Sánchez. Potential use of ozone in SARS-CoV-2 / COVID-19. Official Expert Opinion of the International Scientific Committee of Ozone Therapy (ISCO3). ISCO3/EPI/00/04 (March 14, 2020). Approved by ISCO3 on 13.03.2020. P. 15.

7. Yu.V. Filippov and others. Electrosynthesis of ozone // Publishing house of Moscow State University, 1987. P. 21.

8. E.M. Silkin Synthesis of ozone in electrical discharges and increasing its efficiency // Components and technologies. No. 6. 2008. P. 136-143.

9. A.V. Tokarev, A.Yu. Makhkambaev. Synthesis of ozone in a combined discharge with a plasma induction electrode. Bulletin of KRSU. 2006. Volume 6. No. 5. P. 16-19.

10. V.G. Samoilovich, L.Yu. Abramovich Arguments "for" and "against" the use of air or oxygen for the industrial production of ozone // First All-Russian Conference "Ozone and other environmentally friendly oxidants" Materials conference, M. 2005. S. 144.

11. R.H. Amirov, E.I. Asinovsky, I.S. Samoilov, A.V. Shepelin. The characteristics of ozone generation from air by nanosecond corona discharge // 20 Int. Conf. Phenom. Ionized Gases, II Ciocco, 8th-12th July, 1991: Contrib. Pap. 1. Pisa, 1991. P. 279-280.

12. A.V. Tokarev Determination of the characteristics of a corona flare discharge as a source of ozone production, abstract of Ph.D. dis. ... Cand. physical-mat. Sciences: 01.04.14. Bishkek, 2000. 146 p.

13. W.J.M. Samaranayake, Y.Miyahara, T.Namihira, S.Katsuki, T.Sakugawal, R.Hackad, H.Akiyama. Pulsed Streamer Discharge Characteristics of Ozone Production in Dry Air // ZEEE Traitsactions on Dielectrics and Electrical lnsulafion. Vol. 7. No. 2, April 2000. P. 254-260.

14. A.A. Mynka, N.P. Polyakov. Method for the synthesis of ozone and a device for its implementation / Patent No. RU2220093C2.

15. Yu.V. Filippov, V.A. Voblikova, V.I. Panteleev Electrosynthesis of ozone. M.: Publishing house of Moscow State University, 1987.

16. V.V. Lunin, N.V. Karyagin, S.N. Tkachenko Methods for producing ozone and modern design of ozonizers: Textbook. M.: Max Press, 2008.

17. P.2346886RF, MKI S01V13 / 11. Ozone generator / E.M. Silkin. Publ. B.I. 2009. No. 5.

18. V.A. Voblikova, E.A. Shabrova, E.V. Shabrova. Optimization of ozone synthesis using special dielectric materials and increased current frequency // Abstracts of reports. Russian conference dedicated to ozone and other environmentally friendly oxidants, science and technology. Moscow. June 7-9, 2005.

19. V.V. Lunin, V.I. Gibalov, I.S. Tkachenko Ozone synthesis in a surface barrier discharge in oxygen // Abstracts of reports. Russian seminar dedicated to ozone and other environmentally friendly oxidants. Moscow. June 18-19, 2008.

20. Dingkun Yuan, Can Ding, Yong He, Zhihua Wang, Sunel Kumar, Yanqun Zhu \&Kefa Cen. Characteristics of Dielectric Barrier Discharge Ozone Synthesis for Different Pulse Modes // Plasma Chemistry and Plasma Processing Vol. 37, P. 1165-1173 (2017). 
21. I.S. Tkachenko. Modeling the synthesis of ozone in a surface barrier discharge in oxygen / Author's abstract of the dissertation for the degree of candidate of physical and mathematical sciences 02.00.04. Physical chemistry. Moscow, 2010. 23 p.

22. V.V. Andreev, Yu.P. Pichugin Effect of voltage polarity on ozone synthesis in a dielectric barrier discharge. - Applied Physics. 2017 (3). S. 47-51.

23. V.V. Andreev, A.N. Matyunin, Yu.P. Pichugin, V.G. Telegin, G.G. Telegin. Investigation of the efficiency of plasma-chemical ozone generators based on a barrier discharge in air at atmospheric pressure. VANT. Ser. Thermonuclear fusion. 2011, No. 4. P. 112-117.

24. M.F. Zhukov, A.S. Koroteev, B.A. Uryukov. Applied dynamics of thermal plasm / Novosibirsk: "Science" SB AN. 1975. 299 p.

25. G.Yu. Dautov, M.I. Sazonov. Electric field strength in a vortex-stabilized arc. PMTF, No. 4, 1967. S. 127-131.

26. A.F. Bublievsky. Criteria dependencies for non-consumable electric arcs in the channel // IFZh. 1997. T. 70, No. 1. P. 99-104.

27. A.I. Veremeychik, M.I. Sazonov, D.L. Tsyganov. Study of an electric arc in a helium flow in a high-current plasmatron // Instruments and experimental techniques. 2006. No. 5. P. 99-102.

28. V. V. Batrak, A. I. Veremeychik, M. I. Sazonov, V. M. Khvisevich. Investigation of an electric arc in an argon flow / // Bulletin of Brest. state tech. university. 2008. No. 4: Mechanical engineering. S. 26-28. 